\title{
Palabora Lift 1 block cave: understanding the grade behaviour
}

\author{
T Diering Dassault Systèmes, Canada \\ SN Ngidi Palabora Mining Company, South Africa \\ JJ Bezuidenhout Palabora Mining Company, South Africa \\ HD Paetzold Palabora Mining Company, South Africa
}

\begin{abstract}
Palabora Mining Company commenced mining of the Lift 1 block cave in 2001. Lift 1 is now nearing completion, and this paper will discuss the challenges around the reconciliation and forecasting of grades during the life of Lift 1. Particular emphasis will be placed on the impact of the open pit failure which took place in 2004 and its impact on the grades later on in Lift 1.

The paper will look at the different caving mechanisms which have contributed to, and impacted on, the recovered metal from the block cave. It will also look at how the cave management was impacted by the coarse fragmentation of the cave, which was a first worldwide at the time, and the interaction between practical mining constraints and idealised caving strategies.

In the latter stages of the mine, some particularly surprising grade behaviour was experienced, and plausible explanations for this behaviour will be presented relating to the open pit failure material and cave back shapes.

Concluding remarks will discuss how the experiences learned from Palabora Lift 1 can potentially benefit Palabora Lift 2 and other future caving operations.
\end{abstract}

Keywords: Palabora block cave, caving mechanism evaluation, reconciliation

\section{Introduction}

The Palabora Igneous Complex is an Archaean foskorite-carbonatite pipe complex with an area of $20 \mathrm{~km}^{2}$ that resulted from an alkaline intrusive cycle which emplaced, in successive stages, pyroxenite, syenite, and ultramafic pegmatoids, within a granite and gneiss terrain. The copper orebody is an elliptically shaped vertical pipe of about $1 \mathrm{~km}^{2}$ area intruded at a late stage into the central core of the complex, and consisting of foskorite and carbonatite (sövite) rock types. These feature iron and copper mineralisation, typically comprising minerals such as magnetite, bornite and chalcopyrite. Considerably later than the formation of the complex, the area was crossed by numerous Karroo dolerite dykes, with a northeast to southwest trend.

Economic copper mineralisation is found in just one part of the Palabora Complex; a vertical pipe consisting of four more or less concentric intrusive units that are crossed by the later barren dolerite (DOL) dykes. These units have been identified from the now mined out surface at $480 \mathrm{~m}$ elevation down to about $-1,300 \mathrm{~m}$, a total span of $1,780 \mathrm{~m}$, with no evidence of the deposit bottoming out.

The outermost and earliest of the units, the micaceous pyroxenite (MPY) forms the majority of the complex, with sub-economic copper and magnetite grades, and is considered to be peripheral to the copper deposit. The ore-bearing units have higher magnetite grades between 5 and $40 \%$ magnetite, and copper grades between 0.1 and $1.5 \%$ copper. The copper grades increase towards the centre of the intrusion associated with the transgressive carbonatite (Figure 1). The inverse is true for the magnetite where the grades increase to the edge of the intrusion where the highest percentage of magnetite is 
associated with the foskorite rock. Refer to Figure 1 for the approximate areal extents across the centre of the orebody:

- Foskorite (FOS), east-west more than 1,300 m, north-south $750 \mathrm{~m}$.

- Banded carbonatite (BCB), east-west 1,000 m, north-south $500 \mathrm{~m}$.

- Transgressive carbonatite (TCB), east-west $600 \mathrm{~m}$, north-south $120 \mathrm{~m}$.

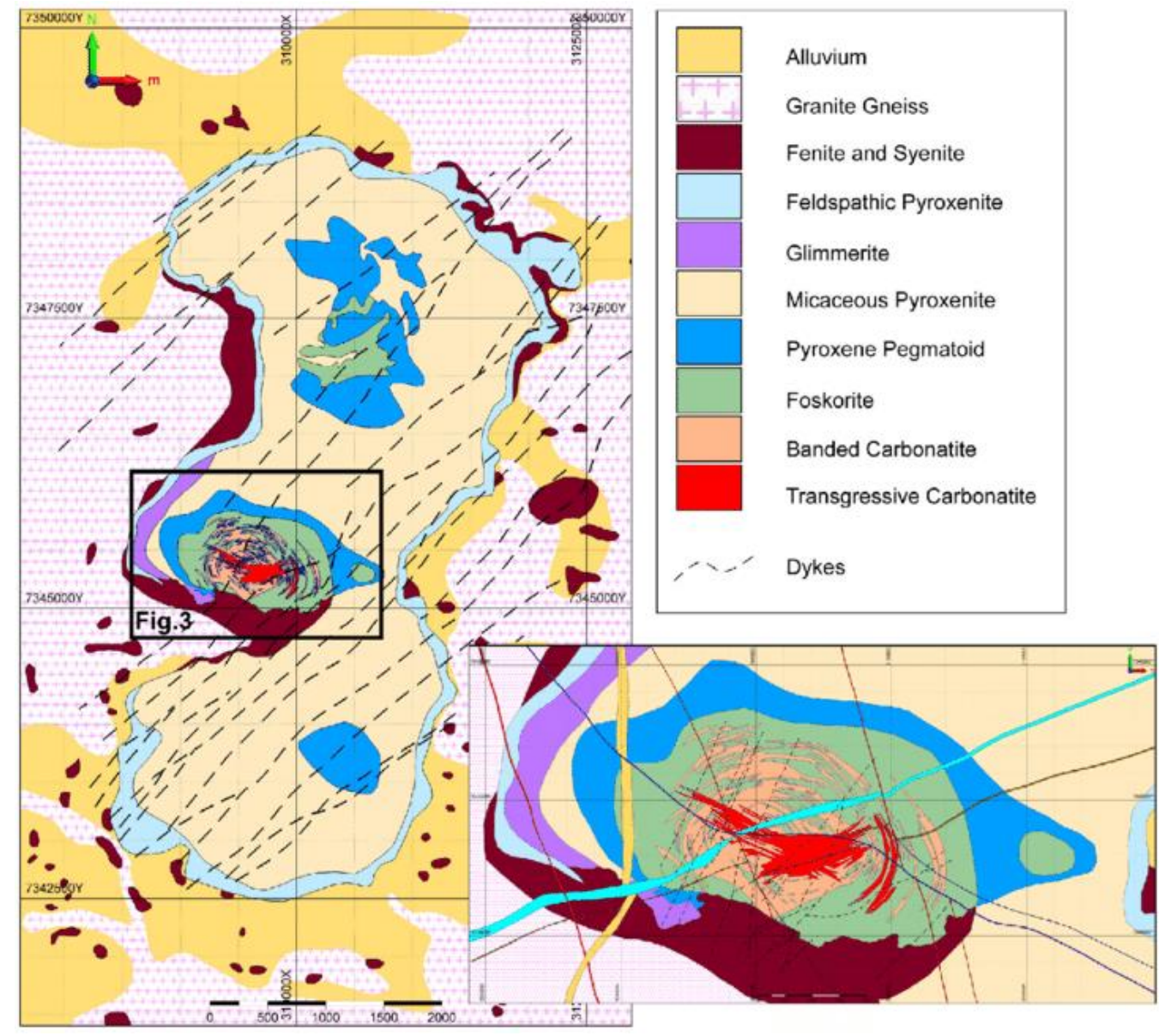

Figure 1 Local geology (Vervoerd 1967)

From the initial block cave production in early 2001, Palabora faced a number of challenges; some of them unique in block cave mining history at that time. The early mining and challenges around the strong rock and coarse fragmentation have been summarised in previous publications (Ngidi \& Pretorius 2010). In this paper, we consider the impact of various factors on grade prediction and related metal recovery - each of which is described in more detail in the body of the paper:

- Early issues with the resource model.

- Dolerite versus ore mining-related issues.

- Cave propagation and hole through into the open pit.

- The pit failure in 2004.

- Factors impacting grades post pit failure.

- Reserves adjustment in 2006.

- Grade reduction from 2006 to 2013.

- Grade profile post 2013. 
The behaviour of the grade profile post 2013 is the most interesting and is covered in some detail. Bezuidenhout (2018) has covered much of the grade reconciliation history in his Masters research thesis.

\section{$2 \quad$ Nomenclature}

For purposes of this paper, we define the following:

- Mill grades. The grades based on actual copper samples from the mill. A monthly reconciled value is made available which is considered the best estimate of what has been mined from the block cave drawpoints.

- Assay grades. These are based on drawpoint assays which are tonnage weighted to provide an average monthly estimate based on drawpoints.

- PCBC (Personal Computer Block Cave) is a software package used by virtually every mining company involved in caving for mine planning and scheduling.

- Model grades. These are based on PCBC analysis using a geological block model as input and to which various material mixing algorithms are applied.

\section{$3 \quad$ Early issues with the mineral resource block model}

Grade behaviour is difficult to reconcile in the early stages of any block cave (in this case, 2001-2005). However, once this initial period had passed, it soon became apparent that the grades being received from the mill (head grade) were lower than PCBC forecasts (Figure 2). This was obviously a concern, and a number of studies were initiated to understand the contributing factors. There were three initial factors for the discrepancy:

- The mixing/flow algorithms within PCBC which generate the grades (using the resource block model as input).

- The mining process.

- The mineral resource block model estimates.

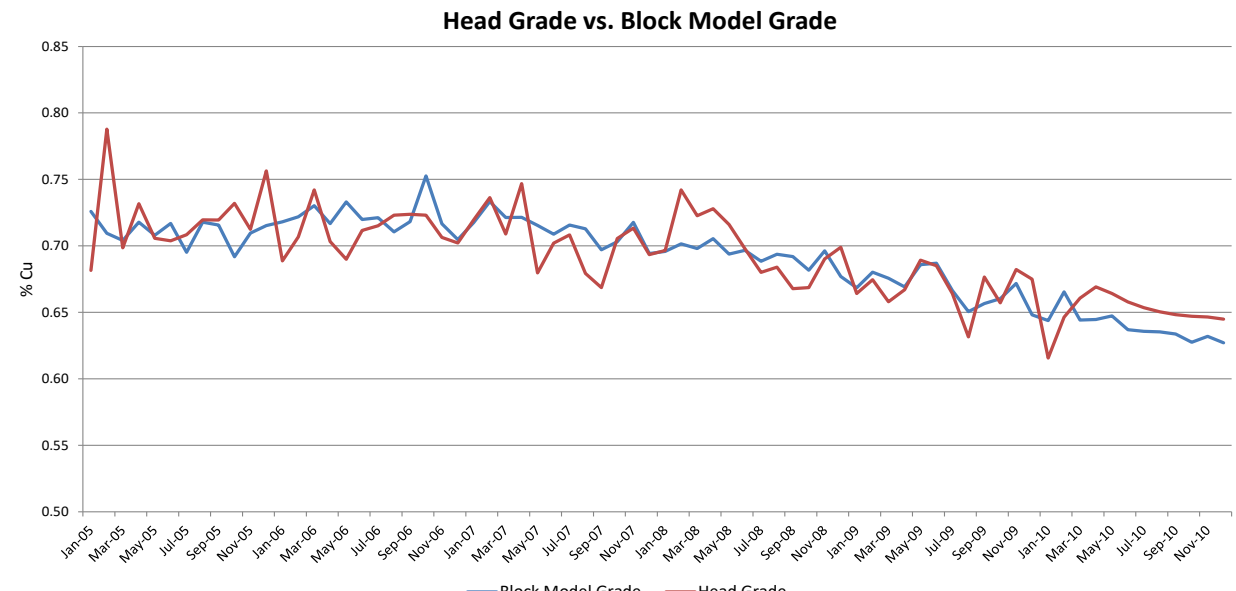

Figure 2 The comparison of head grade versus the PCBC model grade

It is also worth noting that during the early years of cave mining at Palabora, drawpoints were not sampled on a regular basis. Thus, at that stage there was no way to compare drawpoint grades to mill grades. Assay sampling from drawpoints was undertaken from April to June in 2008 by the geological department and were deemed to be consistent. 
PCBC takes historical tonnes mined per drawpoint and, using a slice file (Diering 2000), it will produce an estimate of the grades to be mined by applying one of several mixing algorithms. In the early work, the pre--vertical mixing algorithm was used. With this algorithm, it is relatively easy to simulate mixing by changing the mixing horizon and related parameters. Several iterations were undertaken to obtain a better match between model and mill grades. These initial efforts were unsuccessful. The basic conclusion from this was that if we mixed high-grade material with the similar high-grade material we still ended up with high-grade material. In other words, there were not enough sources of low-grade material to enable calibration to lower the grades. The available sources of low-grade model would be either low-grade external blocks, some internal low-grade blocks, or blocks with high dolerite content.

In the early years (2001-2005), considerable focus was placed around the mining process (which was very difficult). The overall production target for Palabora had been set to $33 \mathrm{kt}$ per day which, from 332 drawpoints, amounted to around $100 \mathrm{t}$ per drawpoint per day. In principle, this is an acceptable target, but the coarse initial fragmentation resulted in less than $30 \%$ of drawpoints being available for production on any given day. At the same time, there were production requirements which dictated that maximum tonnes be produced to achieve the official production target. This, in turn, drove a mining strategy which is sub-optimal to the traditional draw control strategies of even draw over all drawpoints. To make matters worse, drawpoints with good fragmentation were also those with the highest dolerite (internal dilution) content. There was a temptation to extract more tonnes from lower grade drawpoints which would result in lower mill grades/tonnes to achieve the mill capacity target. Tonnes mined per drawpoint was monitored using Modular Mining Dispatch system, so theoretically, every tonne mined would be correctly recorded. However, initial teething problems, and general day to day operations meant that tonnes recorded were also subject to uncertainties. Various studies around dolerite content suggested that the block model might require revision.

There were a number of interesting features in the early block models used for the underground mining process:

- Drill spacing was insufficient for the final block cave footprint. Additional drilling had been completed prior to the final underground designs, with the aim of delineating a much more extensive underground target. However, the final footprint reduced in size resulting in fewer holes in the final footprint geometry.

- The geology is complex, such that it was not possible at that time to build detailed geological domains for rock type based kriging.

- During the modelling, the dolerite dykes overlayed the mineralised model. Thus, the kriging process was done in two stages. Dolerite samples were removed from the samples, and the remaining assays were used to estimate blocks in the model assuming no dolerite presence. The model was then adjusted using a percentage of dolerite within each block. Thus, a block might be estimated at $1 \%$ copper, but if, subsequently, $50 \%$ of the block is estimated to be dolerite, the final grade would be $0.5 \%$ copper.

- To further complicate issues, the higher copper grades are associated with higher density material, so appropriate density weighting in the estimation process was required.

- The block model orientation and size had been set up to match with the drawpoint orientation and spacing. The block sizes were $20 \times 40 \times 60 \mathrm{~m}$, and Howson (2003) suggested that the block sizes had to be revised to $10 \times 10 \times 10 \mathrm{~m}$. The exploration drill density for Lift 2 justified the reduction in block size. This would give a higher resolution to the block model, especially in the case of the dolerite dykes with a zero grade value.

After much analysis (Bezuidenhout 2018; Howson 2003, 2004a, b, c), a new block model was created using simple kriging, which provided better agreement between model and mill grades. 


\subsection{Dolerite-related mining issues}

Particularly during the early stages, and periodically throughout the whole of Lift 1 , dolerite and the mining thereof has been problematic:

- Dolerite undergoes finer fragmentation than the surrounding ore material. This, in turn, means it is easier to mine and flows quicker to the drawpoints.

- Dolerite impacts on the material mixing and general cave propagation process. Questions were raised as to how quickly the cave might propagate above or within dolerite dykes and how the material might migrate to adjacent drawpoints.

- The modelling of dolerite was difficult as mentioned in the previous section.

- Detection and quantification of dolerite content in the mill feed, for reconciliation purposes, was difficult. All underground material was fed through the mills. During the milling process the dolerite would build up in the mills up to a point, when it is then removed as 'tap offs'. The tap offs were stockpiled to be processed at a later stage.

- Early in the life of Lift 1, crosscut 11 became unserviceable due to poor ground conditions including high dolerite content which may have been overstressed (Figure 3). From a modelling perspective, this adds the additional complication of trying to account for the ore material above the now defunct crosscut 11 drawpoints.

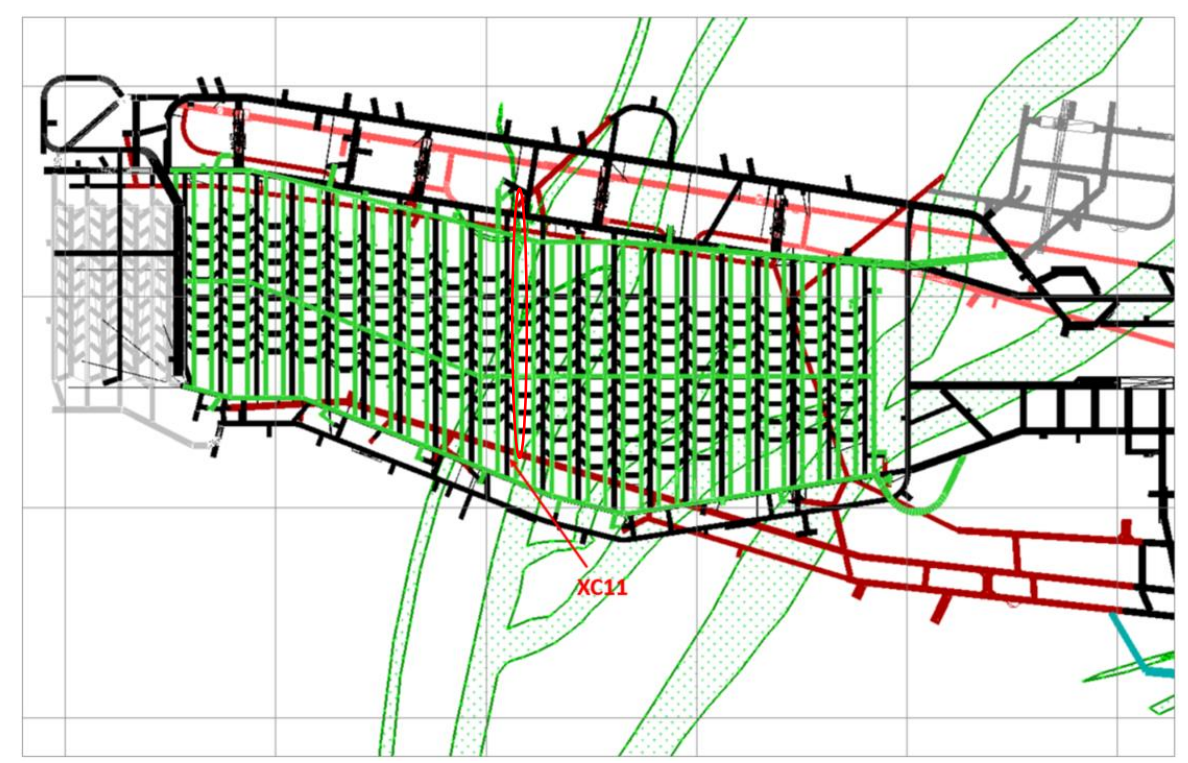

Figure 3 Plan showing modelled dolerite intrusions

However, with time, the treatment and tracking of dolerite material improved and was managed effectively.

\subsection{Cave propagation and break through into the open pit}

The original concept for the cave propagation for Lift 1 was that the cave would propagate up and into the open pit. The undercut sequencing was designed to facilitate this process by initiating in a diamond pattern in the centre, known to be the weakest and highest dolerite content zone. Thus, it was expected that initial propagation would be from the centre of the cave towards the centre of the pit (Figure 4) However, the original concept was that the cave would gradually widen out to have sub-vertical sides allowing full recovery of ore and ultimately into a cave with around 80 degree slopes allowing for additional recovery of additional copper from the abutments of the cave. There was sufficient confidence in this approach that this material was included in the original reserves statements as toppling reserves. 


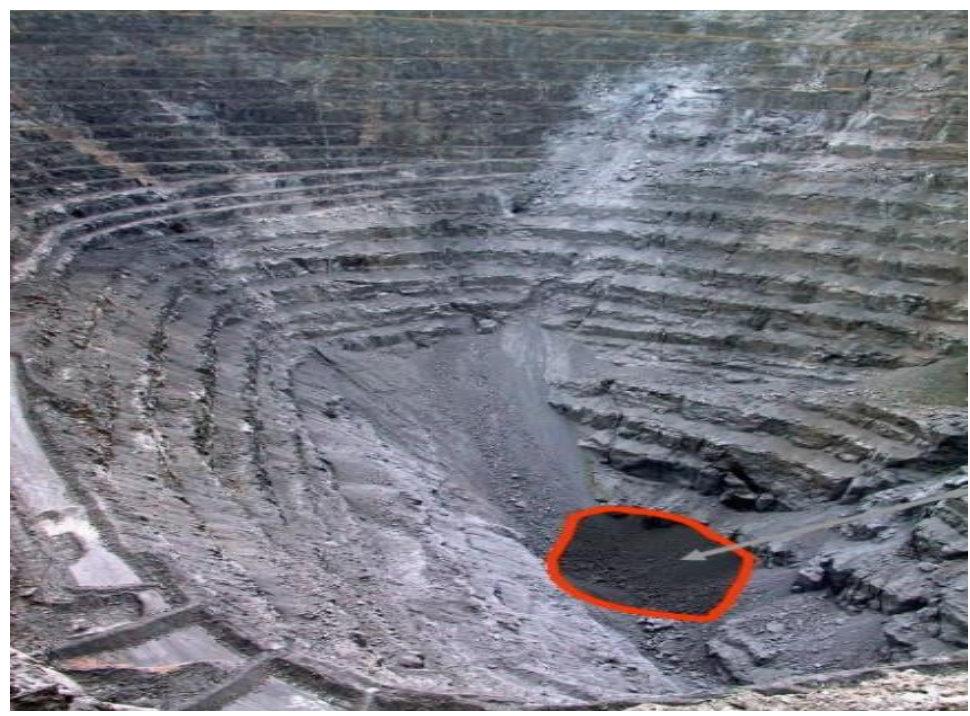

Figure 4 Initial break through

\subsection{Pit failure in 2004}

Original assessments of the open pit/underground interaction had suggested that the pit would largely remain intact. However, in mid-2004, progressive pit wall instability was observed in the northwest sector of the pit which shortly after resulted in a massive slope failure of over $100 \mathrm{Mt}$ into the bottom of the pit entirely covering the subsidence zone above the top of the cave (Figure 5).

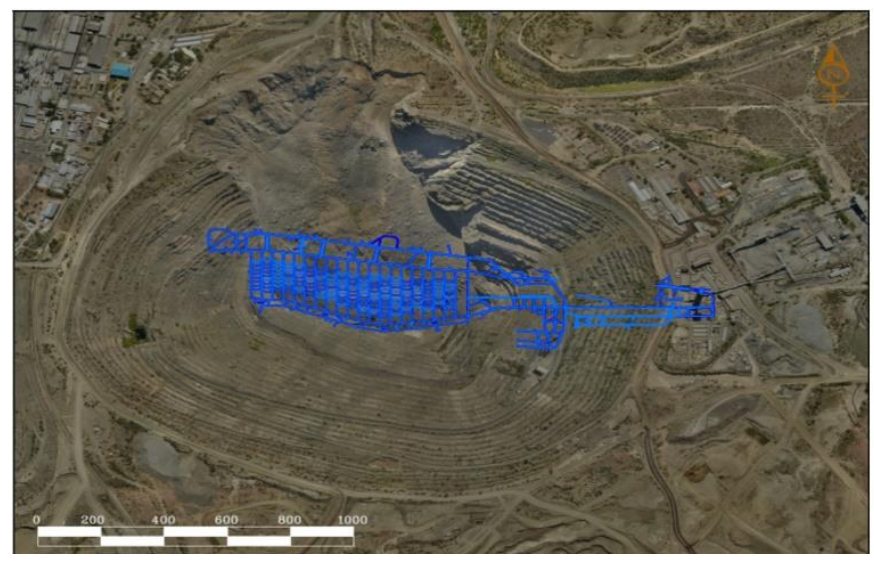

Figure 5 Open pit failure with the underlying Lift 1 production level

The pit failure effectively changed the entire future outlook for the Lift 1 block cave. There were obvious concerns about the impact to other surface installations and infrastructure, but this is not the subject of this paper. The grade implications, however, were substantial, and are the subject of this paper.

- The pit failure was perceived as an almost infinite source of waste material with generally fine fragmentation which posed a high risk to propagate rapidly into the cave, adding unwanted dilution into the drawpoints sooner than initially expected.

- The second significant implication was that with the pit failure material flowing into the top of the cave, further growth of the cave abutment would be inhibited, thereby sterilising ore material.

It became clear that considerable re-work of the PCBC and related ore reserve models would be required to take account of the pit failure and new dilution source. 


\subsection{Factors impacting grades post pit failure}

To some extent, the evolution of the modelling process at Palabora tracks with the modelling capabilities of the PCBC software (Diering 2007). From experience at Palabora and several other block cave mines, it had become quite apparent that the cave flow and modelling behaviour was relatively different from a conventional large soft rock type panel cave operation. However, as the cave behaviour and corresponding tool sets were all quite new, there were not many case studies on which to base the ongoing Palabora modelling.

Diering (2007) outlined the following core cave flow mechanisms from a modelling perspective:

- Normal vertical mixing (as outlined in early works by Laubscher 2000).

- Horizontal mixing via a diffusion-like process.

- Rilling. Lateral movement of caved material beneath a solid overhanging cave back.

- Toppling. Lateral movement of broken open pit material into the top of the cave.

- Inclined flow as indicated on the sides of kimberlite pipes would generally be limited to be close to vertical, but non-vertical, nevertheless.

- Fines migration, which is a percolation-like behaviour that would permit finer broken material high in the cave to move through a coarser broken surrounding cave mass at an accelerated rate.

- Chimneying, a mechanism first described by Laubscher (1994) resulting from excessive uneven draw. This enables a direct route from drawpoints up to overlying fines material which can then merely flow via an established pathway into drawpoints as dilution.

The above are shown schematically in Figure 6.

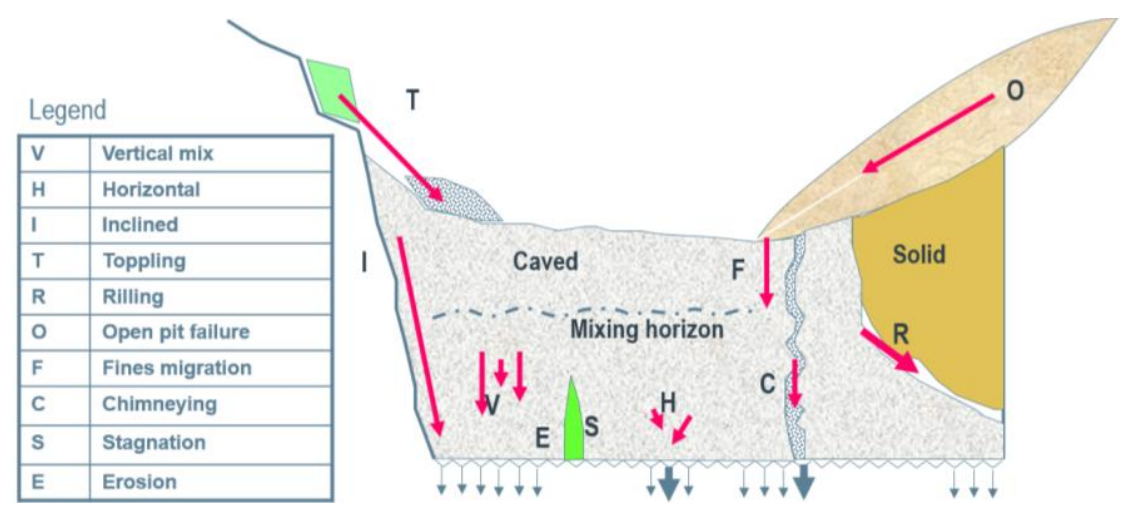

Figure 6 Schematic of various material flow mechanisms in a block cave (Diering et al. 2010)

After the pit failure, these various flow mechanisms were introduced into the PCBC model for Palabora. Previous vertical mixing settings were used, but rilling would take place beneath the overhanging abutments of the cave until they were removed or caved. The rilling material would topple down the sides of the pit failure and then move into the cave, where the fines migration mechanism would accelerate, enabling the pit waste to reach the drawpoints relatively quickly. The material in the upper external extremities of the cave, which was included in the original ore reserve, was now at significant risk of never being recovered. 


\section{$4 \quad$ Reserves adjustment in $\mathbf{2 0 0 6}$}

As a result of the pit failure and the expected post-failure cave behaviour, it was necessary for the mine to issue an ore reserves update. This was issued in early 2006, resulting in a write-down of reserves from 244 to $142 \mathrm{Mt}$, and then to $154 \mathrm{Mt}$. The adjustment had various components:

- $3 \mathrm{Mt}$ were written off due to the loss of access to crosscut 11.

- $60 \mathrm{Mt}$ were written off as a result of the waste material that accumulated at the bottom of the open pit due to the pit failure.

- $30 \mathrm{Mt}$ of waste dilution were added to the reserves.

The original ore reserves included toppling material making up the total of $244 \mathrm{Mt}$. It was believed that the pit walls would not fail in the way it did. It was expected that as the material was depleted, the 'shoulders' would start to topple on top of the subsiding ore as the draw continued on the extraction level. Toppling material constituted about $90 \mathrm{Mt}$ of the total ore reserves.

Following the failure in 2004, original projections had to be re-modelled and updated. Existing block model and the PCBC assumptions were changed to accommodate the waste material that would cut off toppling reserves and significantly reduce the life-of-mine. Figure 7 shows how waste failure material was expected to impact the orebody. The finer material was expected to infiltrate the broken cave material in about two years, resulting in a drastic reduction in copper grades.

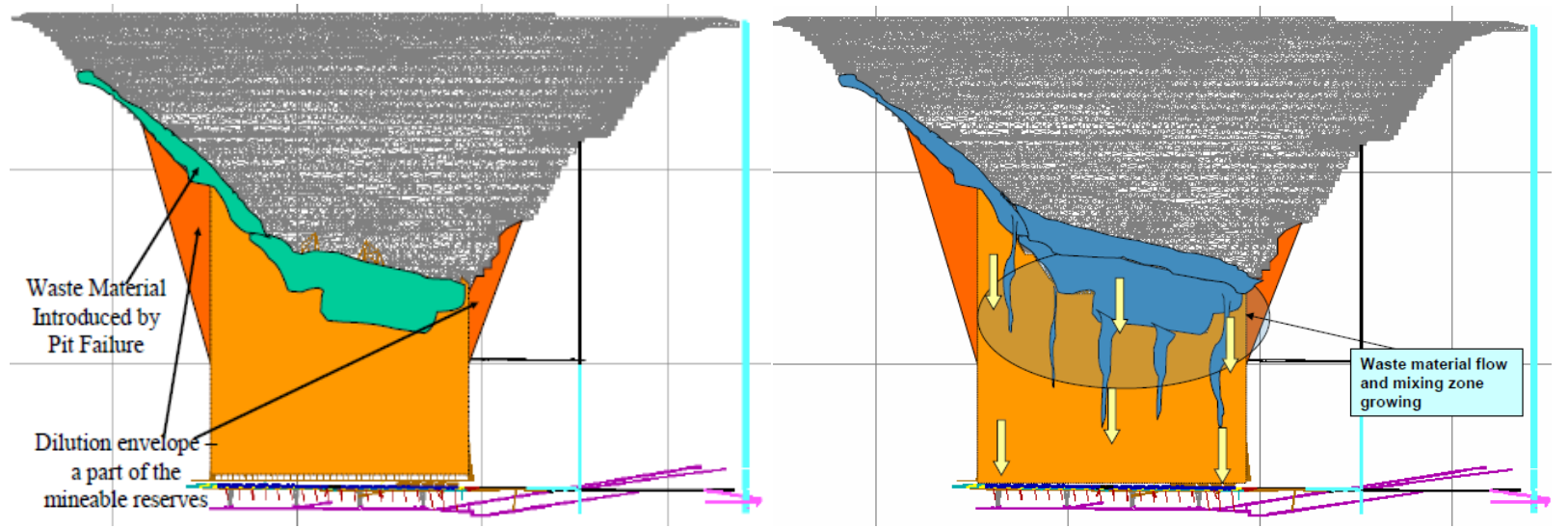

Figure 7 Impact of pit failure material on toppling material and early dilution entry

Initial PCBC runs indicated that only $142 \mathrm{Mt}$ of ore was remaining. This total was later increased to $154 \mathrm{Mt}$, resulting in a nine year reduction of mine life. The projected end of Lift 1 was reduced from 2023 to end 2015.

\subsection{Grade reduction from 2006 to 2013}

It is believed that the first material from the open pit failure arrived at drawpoints sometime in 2006. It was also around this time that the average mill grades started a steady decline which was to continue through to 2013.

As a result of the numerical modelling taking account of the new Lift 1 scenario, the models were refined to provide quite good agreement with mill grade observations which showed a steady downward trend from 2006 to 2013. During that time, a 'central case' was developed (Figure 7) which showed Lift 1 essentially becoming sub-economic during 2016. Life-of-mine for Lift 1 would depend on various factors; one being the chosen shutoff grade, and secondly, the ability to get the proposed Lift 2 up and running. The green and blue lines in Figure 8 showed the typical variability which could be expected based on the assumptions used at that time. 


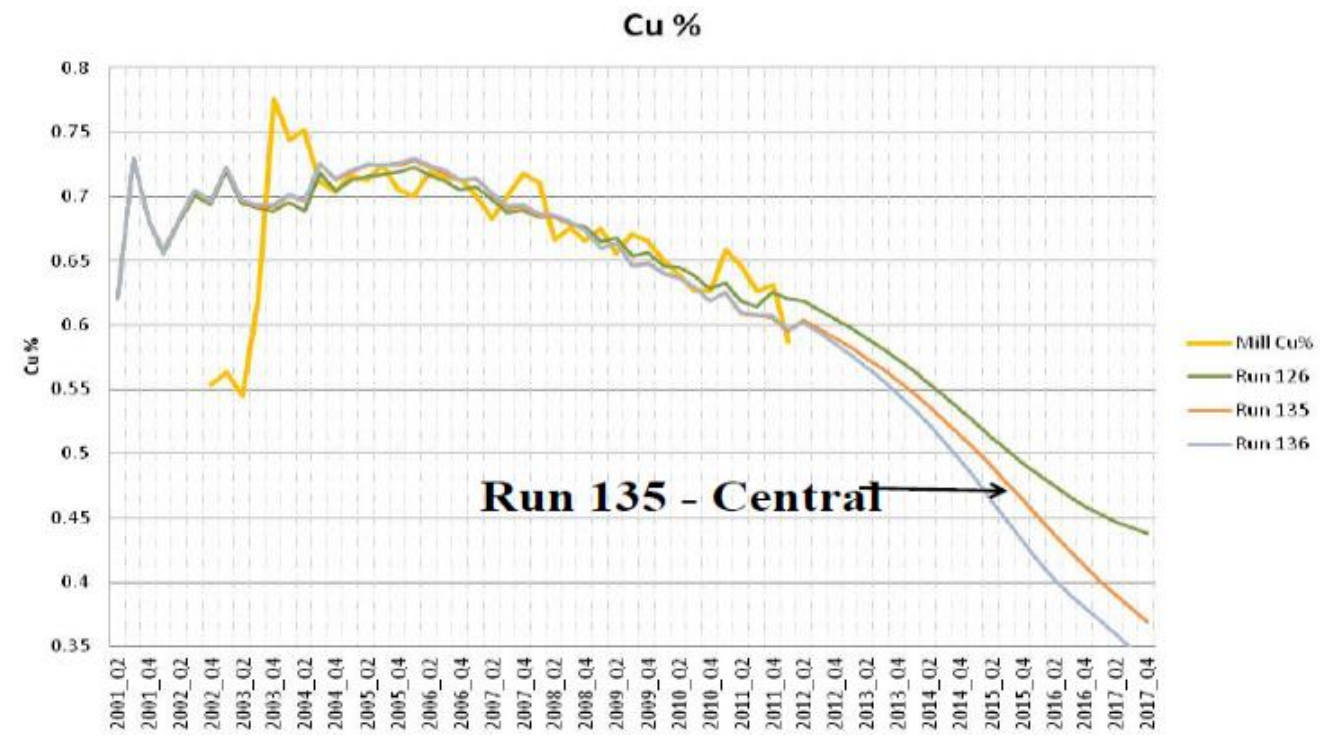

Figure 8 Grade forecast projections from 2011

During that time, changes in the pit failure topography were monitored, and it was clear that material was moving into the top of the cave. However, the actual mechanism by which this material migrated there was subject to considerable discussion. It was also evident from the surface topography movements that the cave shoulders were not getting any wider to free up material from the west and east sides of the cave.

\subsection{Grade profile post 2013}

During 2010, the mill grade started to diverge (in a positive way) from the model grades. By late 2013, it was evident that the model grades were no longer predicting mill grades reliably. Figure 9 shows a considerable divergence $(>10 \%)$ between model and mill grades which started in 2010 but became more significant in late 2014.

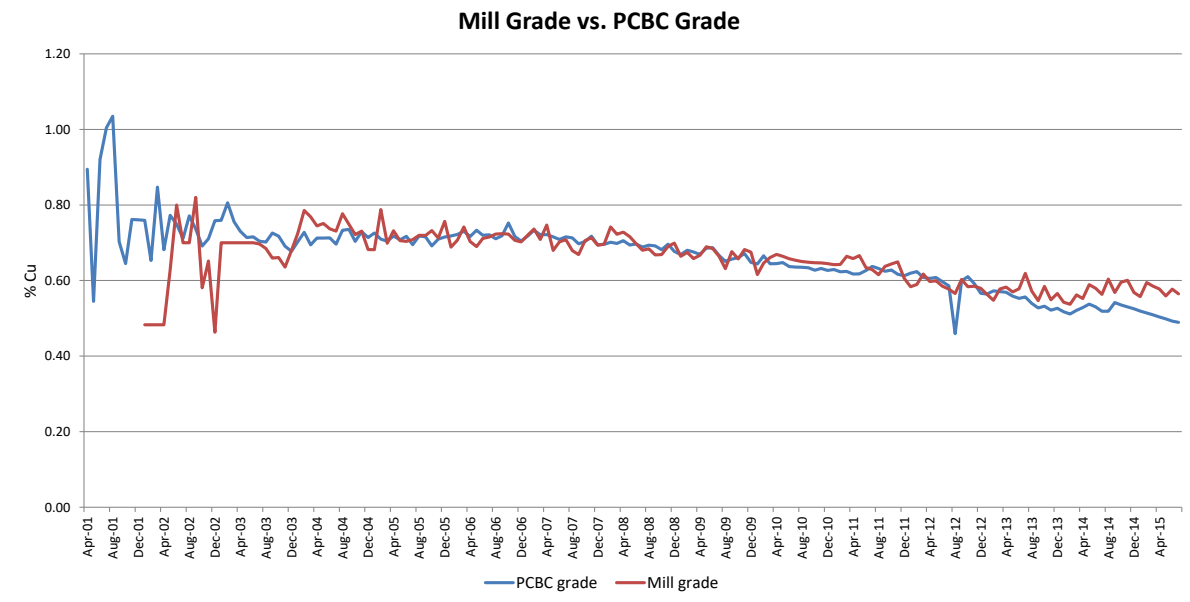

Figure 9 Divergence between the model and mill grades

Also, during the period 2010 to 2014, considerable work was being done in preparation for Lift 2 including added drilling, updates to the geological modelling and kriging methodologies. Some of the improvements to the modelling for Lift 2 were able to be applied to the block model for Lift 1. 


\section{$5 \quad$ Universe approach}

In 2015, another round of calibration and modelling work was done using the latest block model and historical tonnes/grade observations. However, the standard approach of modifying cave backs and flow parameters was not able to replicate the grade stabilisation which had been observed.

Diering and Paetzold worked on a new approach in 2015 which is summarised below:

- Separate the various sources of copper as follows:

- Material originating within the cave zone.

- Material potentially frozen within un-failed cave backs.

- Material originating from the pit wall failure.

- Modelling work had started to indicate that as the anticipated amount of pit failure material now reporting to the drawpoints increased, the variance between the mill and model grades increased. The variance in grades suggest that the pit failure material might contain more copper than expected initially.

- Concurrently, based on observations of the pit surface topography, a possible outline for the sides of the cave back had evolved.

The approach was to define a 'universe' of possible material that could be mined from the cave and to separate this from material outside the universe which is frozen and unlikely to be mined. The universe has defined geometric boundaries consisting of cave outlines below the pit and the pit failure within the pit.

The problem is that very little was known about material within the pit failure zone. The following approach was used to refine the estimate. The top contact and sides of the pit failure surface were known from observations, as was the primary location into which material was flowing out of the pit and into the cave. However, the depth of the failure surface was not known. An estimate was created by connecting known top and bottom points for the failure. The failure volume was then verified against the observed final position of the pit failure in 2004 . The pre- and post-failure volumes were found to match if an average swell factor of $21 \%$ was applied.

To complete the delineation of the universe, refined cave back models were prepared using the undercut outline at the base and observed disturbance at the base of the pit. This also included a general inclination towards the south and the pit failure zone.

Next, was the process to estimate grades into the failure volume. Historical records from drillhole and production mining of the open pit were limited and difficult to locate. However, Paetzold (Palabora Mining Company team leader) and the Palabora Mining Company geotechnical team were able to upload old blasthole data from the open pit in the vicinity of the pit failure. The uploaded data was used with the available drillhole data to re-estimate copper grades in the upper portions of the block model including the lower portions of the pit failure zone. De-clustering techniques were required to balance the large number of blastholes with limited exploration drillholes. Blocks within the universe so constructed are shown in Figure 10. Please note that Figure 10 is coloured by rock type which is not important for this study. 


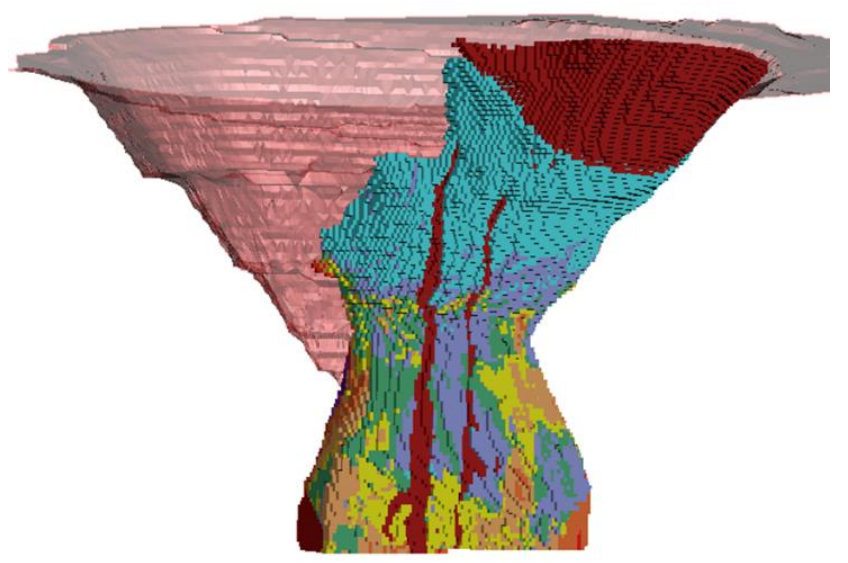

Figure 10 The additional constructed blocks from the open pit failure zone

The next step in the universe approach is to remove all the copper which has ever been mined from the cave. This is done by summarising (mill grades * mill tonnes) for life-of-mine to get total copper. The logic requires that if the copper has not yet been mined from the universe, then it is still available within the remaining universe and could still be mined at some future stage. The processed results are illustrated in Table 1.

Table 1 Calculation table for the tonnes remaining

\begin{tabular}{llll}
\hline Component & Tonnes & Copper (\%) & Metal (tonnes) \\
\hline Cave zone & $165,123,569$ & 0.679 & $1,121,731$ \\
Pit failure zone & $151,169,365$ & 0.143 & 215,971 \\
Total & $316,292,934$ & 0.423 & $1,337,702$ \\
Mined & $-126,886,090$ & 0.661 & $-838,717$ \\
Remaining & $189,406,844$ & 0.263 & 498,985 \\
\hline
\end{tabular}

Key points from this table are as follows:

- $165 \mathrm{Mt}$ inside cave at $0.67 \%$ copper.

- $151 \mathrm{Mt}$ in broken material above the cave at $0.14 \%$ copper.

- Total is $316 \mathrm{Mt}$ at $0.42 \%$ copper.

- Mined is $127 \mathrm{Mt}$ at $0.66 \%$ copper including approximately 839,000 t of copper.

- Remaining is $189 \mathrm{Mt}$ at $0.26 \%$ copper which is approximately $500,000 \mathrm{t}$ of copper.

As a first estimate to test this approach, the following steps were applied:

- Assuming that the remaining material is mined at a constant rate equal to the current mining (12 Mtpa) rate then it would take 15 years to fully deplete the remaining tonnes. Assume that the starting grade is equal to the current observed mill grade $(0.55 \%$ copper).

- Assume that the end grade will be zero (as the last bit of material is extracted).

This gave the grade forecast shown in Figure 11. 


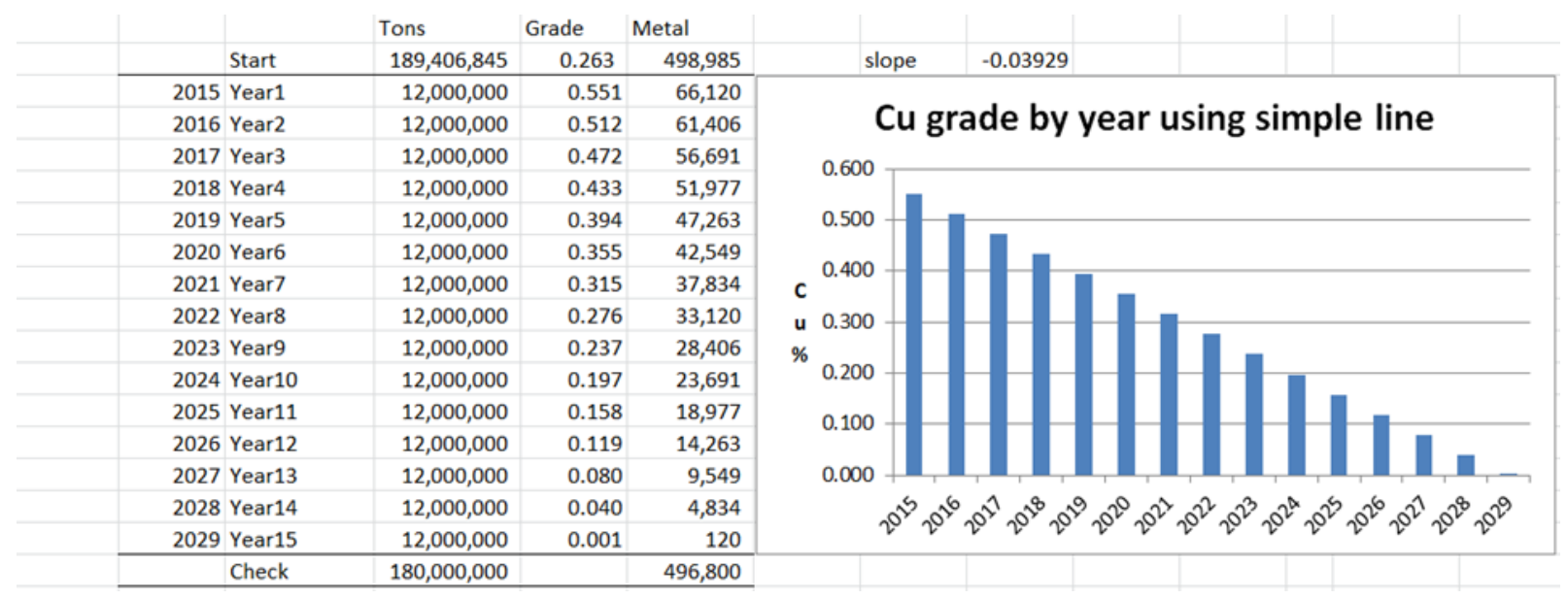

Figure 11 Lift 1 block cave depletion using a straight line from $0.55 \%$ in 2015

This simple forecast shows that a steady decline in copper would be expected to reach approximately $0.40 \%$ copper in 2019 compared to 2016 , or earlier, in previous forecasts.

\section{$6 \quad$ Modelling the pit failure}

The next stage was to build the information and material described above into a PCBC model that could be used for more precise forecasting on a month-to-month basis. By this stage of the Lift 1 mining, PCBC had also evolved, and a new tool called CA3D (Cellular Automaton in 3D) was thought to be suitable for the modelling. It can model rilling below the cave back shoulders and toppling in the open pit, so it seemed to be the ideal tool for the job. The cave back was broken into three progressive stages (dark blue, blue and light blue in Figure 12(a)).

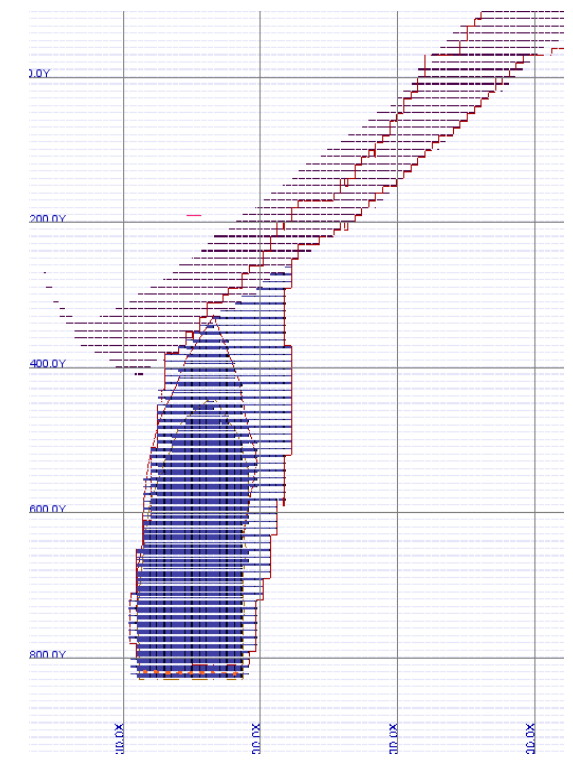

(a)

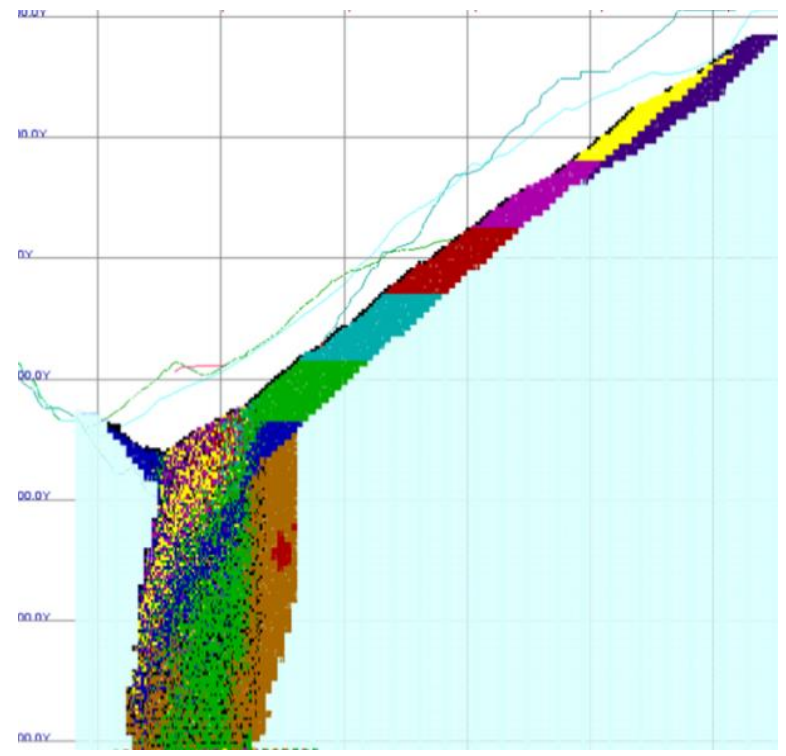

(b)

Figure 12 (a) Three progressive stages of the cave; and, (b) Modelled mix of failure material

Figure 12 (b) shows the CA3D results colored by horizontal bands for clarity. The problem is that although the CA3D results looked impressive, they failed to model observed conditions in a number of places:

- The simulated bottom of pit/failure was much lower than observed. 
- The general erosion/toppling mechanism resulted in the average downward movement of the whole of the failure surface. Observations in Figure 13 showed that the top of the failure surface was moving downwards en masse instead of as observed as the toppling mechanism.

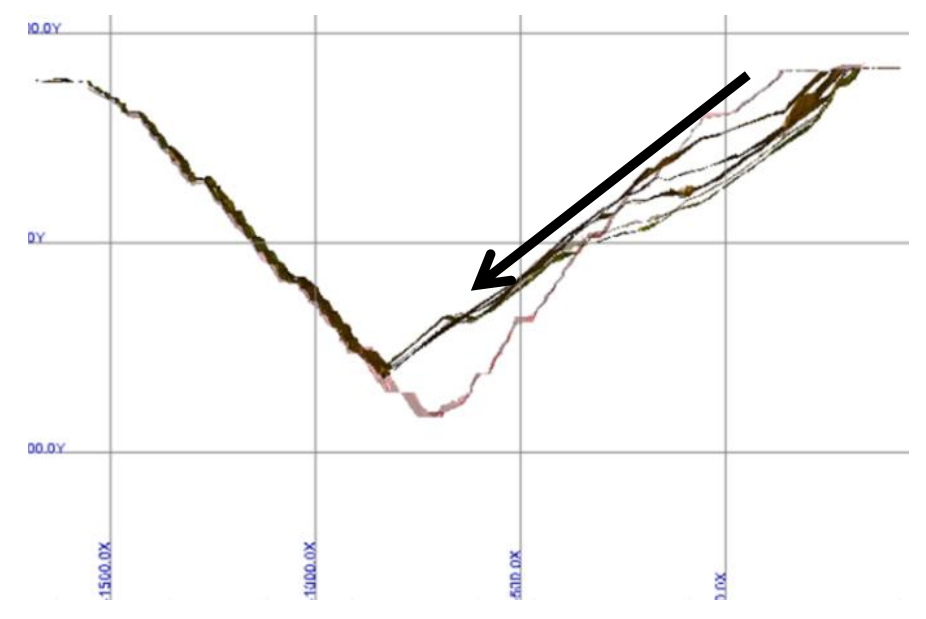

Figure 13 The downwards movement of failure material

- The CA3D model failed to deplete material from the cave zone on the south side of the cave below the pit as the tool was only capable of modelling vertical depletion.

- The overall copper results failed to show what was observed from the mill (Figure 14).

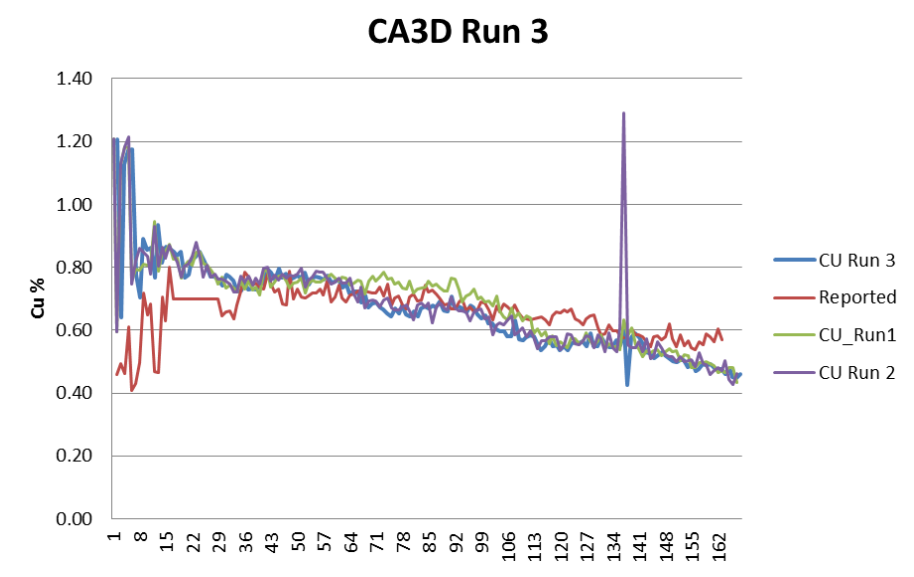

Figure 14 Overall copper results from the CA3D model failing to indicate the actual mill grades

The grade forecast for 2010 to 2014 was still well below mill grades. What this suggested is that the additional copper at the base of the pit failure was not actually finding its way into the cave zone. Instead, much lower grade from much higher in the pit was toppling down the slope into the top of the cave. Although this might seem a reasonable mechanism, it did not match the observations.

\section{$7 \quad$ The glacier concept}

The CA3D modelling suggested that a different flow mechanism was required for the pit failure material. A short search through natural flow mechanisms leads to the idea of treating the pit failure material similarly to glaciers in nature. Figure 15 shows a comparison of the first picture encountered for glacier flow on an internet search (Figure 15(a)) versus the actual pit failure (Figure 15(b)). The resemblance was quite remarkable. 


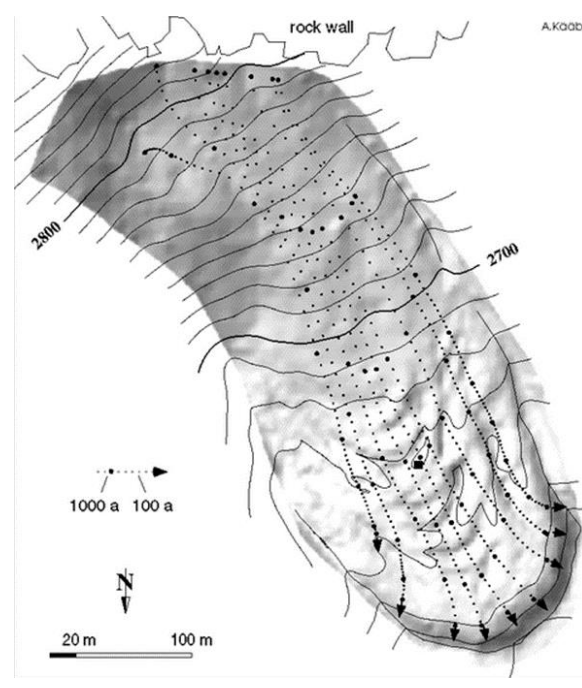

(a)

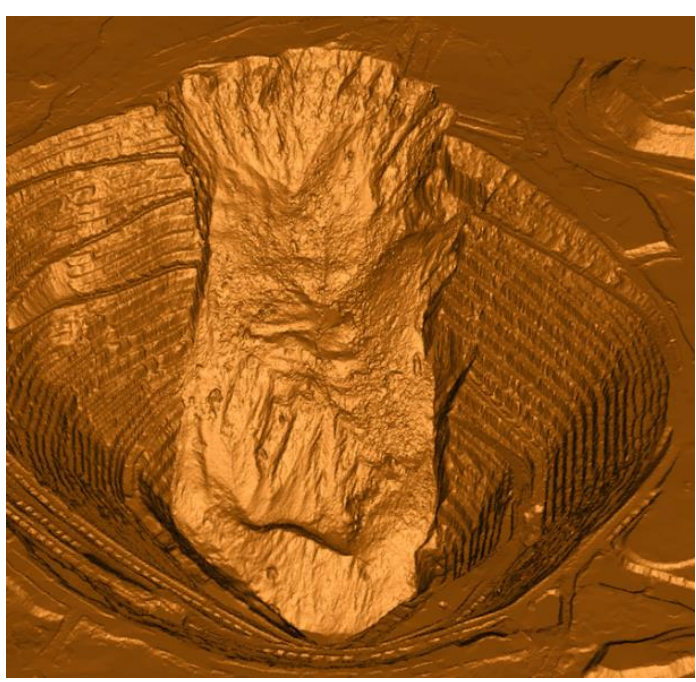

(b)

Figure 15 (a) Glacier flow; and, (b) Actual pit failure resemblance

The glacier movement is driven by melting snow/calving at the base while the pit failure moves due to depletion of material into the cave. The movement direction is en masse parallel to the slope angle.

\section{$8 \quad$ The template mixing model}

The next step was to attempt to build the above observations (variable rilling, non-vertical movement in the cave, and pit failure) into the PCBC template mixing flow model. Rilling and non-vertical movement had been available for several years, but there was no direct way to simulate the glacier-style behaviour. With limited time available, a simplified model was adapted into the program as follows:

- The material in the pit failure was divided into six horizontal slices with material from each slice being evaluated from the block model. These were stored in Excel.

- Draw columns were inclined to match up with the observed cave backs.

- The material in the Excel slices (grey in Figure 16 centre image) were removed from the block model so as to not be counted twice.

- Links were set up from the tops of the draw columns to link to the Excel material.

- The set-up was such that the lower slices in Excel would be fed into the top of the cave in the same order as suggested by the glacier flow.
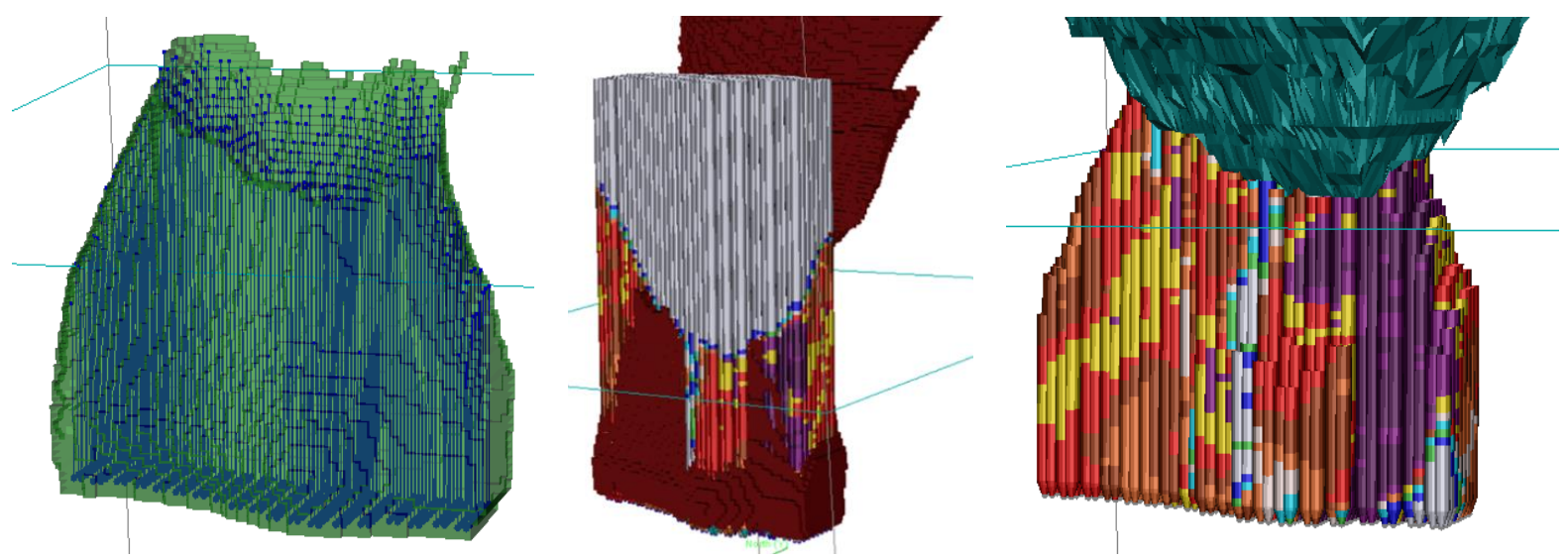

Figure 16 Three views representing construction of the cave zone model 
A few calibration runs were done looking at different time frames for releasing material from the three simulated cave backs yielding the result shown in Figure 17.

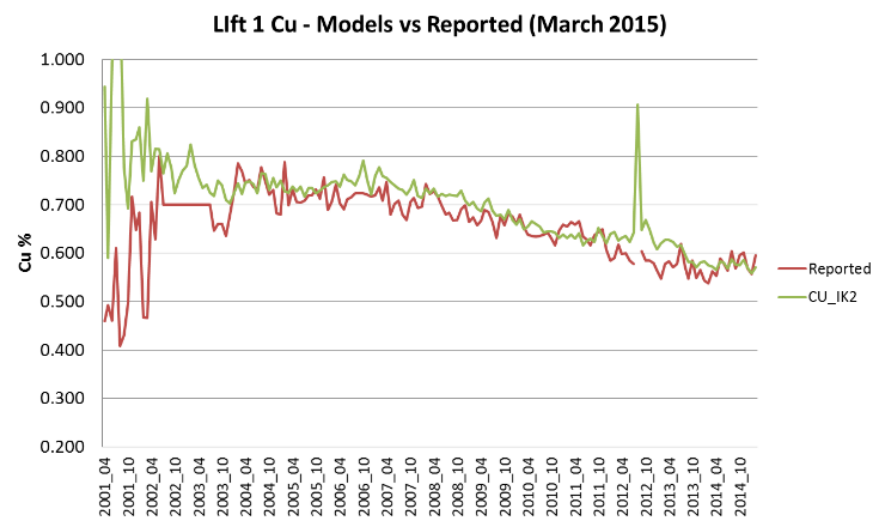

(a)

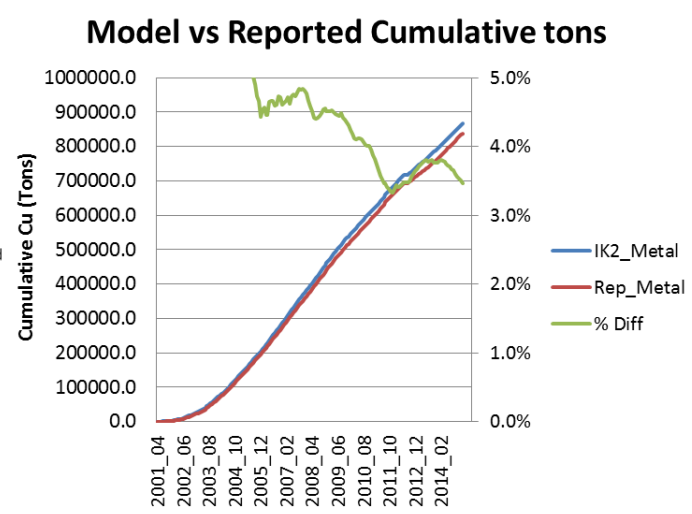

(b)

Figure 17 (a) Lift 1 copper model versus reported grade; and, (b) Model versus reported cumulative metal

It appeared to be the first time that model prediction grades in 2014 were able to match up with the mill grades reported. The total metal balance between extracted by model and mill were within $4 \%$ which was very encouraging.

\subsection{Forecast runs}

From the calibration runs already done, the final step was to forecast copper grades for the next few years at least past the economic end of life for Lift 1. The forecasted results are shown in Figure 18.

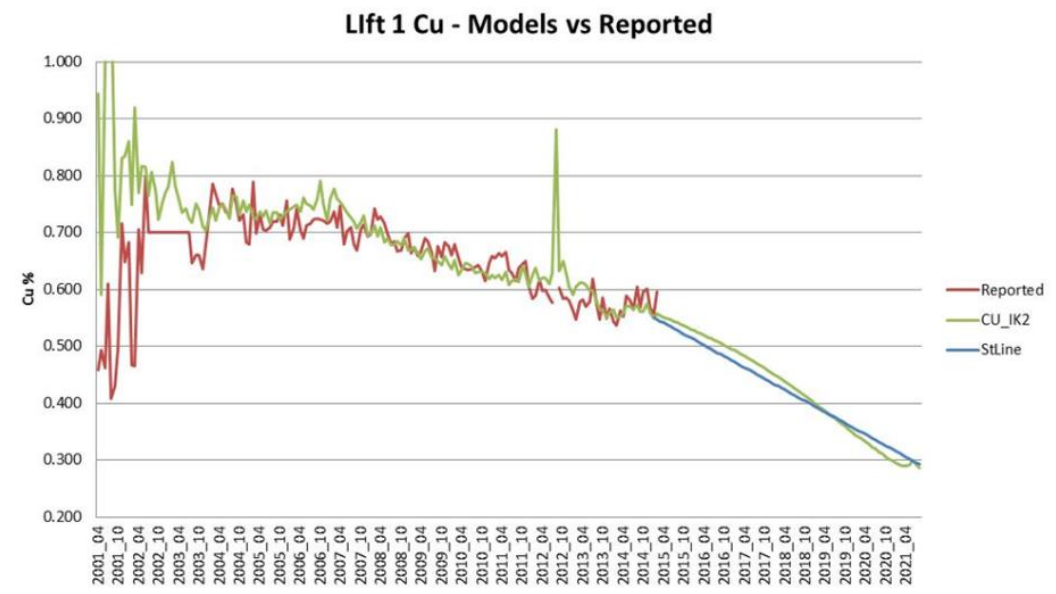

Figure 18 Copper grade results forecasted from 2015 to 2021

The PCBC forecast is remarkably close to the straight line depletion model described earlier. This suggested that the overall approach adopted was likely realistic. It certainly provided a plausible explanation for the observed grade behaviour and was useful for the mine planning personnel to explain the grade behaviour which had previously been inexplicable. 


\section{Conclusion}

Much has been learned from the mining of Palabora Lift 1. The following aspects are important from an operational perspective:

- Collection and retention of all sources of grade data, i.e. blastholes, exploration, mill grades (open pit), etc.

- Maintain an open minded approach when it comes to grade/metal sources.

- Aim to be rigorous on annual grade reconciliations.

- Remove rigid grade estimation techniques, especially towards the end of mine life which may improve the estimation. However, risk and reliability of ore reserves remains high.

From the perspective of grade reconciliation and forecasting, the experience from Lift 1 has shown that calibration is not a one-off event, but should rather be treated as an ongoing routine exercise. Important factors during early years may change and become irrelevant in later years, or vice versa.

The experience for Palabora Lift 1 also demonstrated the complexity of the caving process and the importance of using all available data. The modelling capabilities of the PCBC software package also evolved during the life-of-mine, and fortunately, more complex models were possible in the later years helping to explain the overall grade behaviour.

Two questions remain; if the pit had not failed, could Palabora still have been mining from Lift 1 in 2018/2019, and was the pit failure a disaster or a blessing in disguise?

\section{Acknowledgement}

The authors acknowledge and thank Dassault Systèmes Canada and Palabora Mining Company for the opportunity to prepare this paper. We also thank Palabora Mining Company for permission to use selected results in this paper.

\section{References}

Bezuidenhout, JJ 2018, A Guide for Managing the Resource Model of the Copper Block-cave at Palabora Mining Company, MSc. thesis, The University of the Witwatersrand, Johannesburg.

Diering, T 2000, 'PC-BC: A block cave design and draw control system', in G Chitombo (ed.), Proceedings of MassMin 2000, The Australasian Institute of Mining and Metallurgy, Melbourne pp. 469-484.

Diering, T 2007, 'Template mixing: A depletion engine for block cave scheduling', in EJ Magri (ed.), Proceedings of the 33rd International Symposium on Application of Computers and Operations Research in the Mineral Industry, pp. 313-320, Gecamin, Santiago.

Diering, T, Richter, O, \& Villa, D 2010, 'Block cave production scheduling using PCBC', Proceedings of the SME 2010 Annual Meeting, Society for Mining, Metallurgy \& Exploration, Englewood, pp. 455-467.

Howson, M 2003, Update and Analysis of Palabora's Geological Databases, Rio Tinto Technology Technical Services, Bristol.

Howson, M 2004a, Proposal to PMC to Revise the Geological Data and Resource/Reserve Models, Rio Tinto Technology Technical Services, Bristol.

Howson, M 2004b, Resources, Reserves and Geotechnical Data at Palabora Underground, Rio Tinto Technology Technical Services, Bristol.

Howson, M 2004c, Revision of Palabora Underground Copper and Geology and Resources Data 2004, Rio Tinto Technology Technical Services, Bristol.

Laubscher, DH 1994, 'Cave mining - state of the art', The Journal of The South African Institute of Mining and Metallurgy, vol. 94, no. 10, pp. 279-293.

Laubscher, DH 2000, 'A practical manual on block caving', Block Caving Manual, The University of Queensland, Brisbane, pp. 1-30.

Ngidi, SN \& Pretorius, DD, 2010, 'Impact of poor fragmentation on cave management', in Y Potvin, (ed.), Proceedings of the Second International Symposium on Block and Sublevel Caving, Australian Centre for Geomechanics, Perth, pp. 593-602.

Verwoerd, WJ 1967, The Carbonatites of South Africa and South West Africa, Handbook 6, Council for Geoscience, Pretoria, pp. 16-22. 